\title{
Digital chest drainage system versus traditional chest drainage system after pulmonary resection: a systematic review and meta-analysis
}

\author{
Hong Wang ${ }^{1+}$, Wenbin $\mathrm{Hu}^{2+}$, Liang $\mathrm{Ma}^{2}$ and Yiran Zhang ${ }^{2^{*}}$ (D)
}

\begin{abstract}
Background: Several randomized controlled trials (RCTs) and observational studies have compared the efficacy of digital chest drainage system versus traditional chest drainage system. However, the results were inconsistent.

Methods: We searched the Web of Science and Pubmed for observational studies and RCTs that compared the effect of digital chest drainage system with traditional chest drainage system after pulmonary resection. Eight studies (5 randomized control trails and 3 observational studies) comprising 1487 patients met the eligibility criteria.

Results: Compared with the traditional chest drainage system, digital chest drainage system reduced the risk of prolonged air leak (PAL) $(\mathrm{RR}=0.54,95 \% \mathrm{Cl} 0.40-0.73, p<0.0001)$, and shortened the duration of chest drainage $(\mathrm{SMD}=-0.35,95 \% \mathrm{Cl}-0.60--0.09, p=0.008)$ and length of hospital stay $(\mathrm{SMD}=-0.35$, $95 \% \mathrm{Cl}-0.61--0.09, p=0.007)$ in patients after pulmonary resection.

Conclusions: Digital chest drainage system is expected to benefit patients to attain faster recovery and higher life quality as well as to reduce the risk of postoperative complications. Further RCTs with larger sample size are still needed to more clearly elucidate the advantages of digital chest drainage system.
\end{abstract}

Keywords: Digital chest drainage system, Pulmonary resection, Postoperative care

\section{Introduction}

Alveolar air leak is one of the most frequent complications after pulmonary resection, which happened in up to $50 \%$ patients [1]. Prolonged air leak (PAL), defined as an air leak persisting more than 5 days by the Society of Thoracic Surgeons Database, occurred in approximately $8-15 \%$ patients after pulmonary resection [2]. It had been shown that PAL was associated with longer length of hospital stay, increased hospitalization costs, increased risk of empyema, and other possible cardiopulmonary complications [3, 4]. Thus, better approaches for postoperative care are

\footnotetext{
* Correspondence: zhangyr@zju.edu.cn

${ }^{\dagger}$ Hong Wang and Wenbin Hu contributed equally to this work.

${ }^{2}$ Department of Cardiothoracic Surgery, First Affiliated Hospital, Zhejiang

University School of Medicine, Hangzhou 310003, China

Full list of author information is available at the end of the article
}

needed to optimize the recovery of patients after pulmonary resection.

Traditionally, an analog chest drainage system was used for assessment of the postoperative air leak. However, the traditional chest drainage system has several limitations. On the one hand, it measures air leak in a subjective manner by observing bubbling in the water chamber, thus interobserver disagreement is frequent, and small air leaks are difficult to determine. On the other hand, the suction pressure of the traditional chest drainage system may deviate from the set level due to the position of the water chamber. Recently, a digital chest drainage system has been developed to solve these problems, which uses digital sensors to monitor air flow and pleural pressure continuously [5]. With the digital chest drainage system, the pleural pressure can be constantly maintained by physicians independent of the device position, and postoperative air leak can be evaluated

(c) The Author(s). 2019 Open Access This article is distributed under the terms of the Creative Commons Attribution 4.0 International License (http://creativecommons.org/licenses/by/4.0/), which permits unrestricted use, distribution, and 
objectively. Several randomized controlled trials (RCTs) and observational studies have compared the efficacy of digital chest drainage system versus traditional chest drainage system. However, no meta-analysis has been conducted to pool the results of these clinical trials so far.

A meta-analysis and systematic review was performed to compare the efficacy of digital chest drainage system with traditional chest drainage system.

\section{Materials and methods Eligibility criteria}

The inclusion criteria of literatures in the present meta-analysis were (i) observational studies or randomized trials, (ii) adults ( $\geq 18$ years) undergoing pulmonary resection (including lobectomy, segmentectomy, and wedge resection), (iii) studies comparing digital chest drainage system with traditional chest drainage system, (iv) end points included prolonged air leak (defined as air leak duration $\geq 5$ days), duration of chest drainage and length of hospital stay. The exclusion criteria were: (i) case reports or review articles, (ii) articles written in non-English language.

\section{Search strategy}

A literature search was conducted using the Web of Science and Pubmed to identify relevant literatures published through January 2018. The search term used was "digital thoracic drainage". Two authors (H Wang, W $\mathrm{Hu}$ ) independently applied the eligibility criteria to screen the literature search results, and the reference lists of the included literatures were screened again for more potential studies. Any divergence was resolved by a third reviewer ( $Y$ Zhang).

\section{Data abstraction and quality assessment}

Data abstraction and quality assessment were conducted using methods described previously [6]. Briefly, two authors ( $\mathrm{H}$ Wang, W $\mathrm{Hu}$ ) independently extracted the data and evaluated the quality of the included studies. Any divergence was resolved by a third reviewer ( $Y$ Zhang). The following data was obtained from each study: author, nationality, publication time, number of patients in each study group, study design, baseline characteristics and clinical end points. Two authors evaluated the quality of the included literatures independently. The Newcastle-Ottawa scale was applied to assess the quality of observational studies (http://www.ohri.ca/programs/clinical_epidemiology/ oxford.asp). The following 3 aspects of an observational study were evaluated using Newcastle-Ottawa scale: (1) the selection of the study cohort (or cases/ controls), (2) the comparability of the cohorts (or cases/controls) and (3) the outcome assessment for a cohort study, or the determination of the exposure for a case-control study. The Jadad scale was used to assess the quality of randomized trials [7]. The following aspects of a randomized study were evaluated by the Jadad scale: randomization, double blinding, withdrawals and dropouts. A study was considered as high-quality if its score $\geq 3$. The present meta-analysis and systematic review was conducted following the PRISMA guidelines [8].

\section{Statistical analysis}

The statistical analysis was performed according to previously described methods [6]. Briefly, we use Review Manager 5.2 (RevMan 5.2 ${ }^{\circ}$, Nordic Cochrane Center and Copenhagen, Denmark) to conduct the meta-analysis. We calculated Risk ratios (RRs) with a 95\% confidence interval (CI) using the MantelHaenszel method in order to compare the risk of prolonged air leak between digital chest drainage system and traditional chest drainage system. To investigate continuous measures (duration of chest drainage and length of hospital stay), we calculated

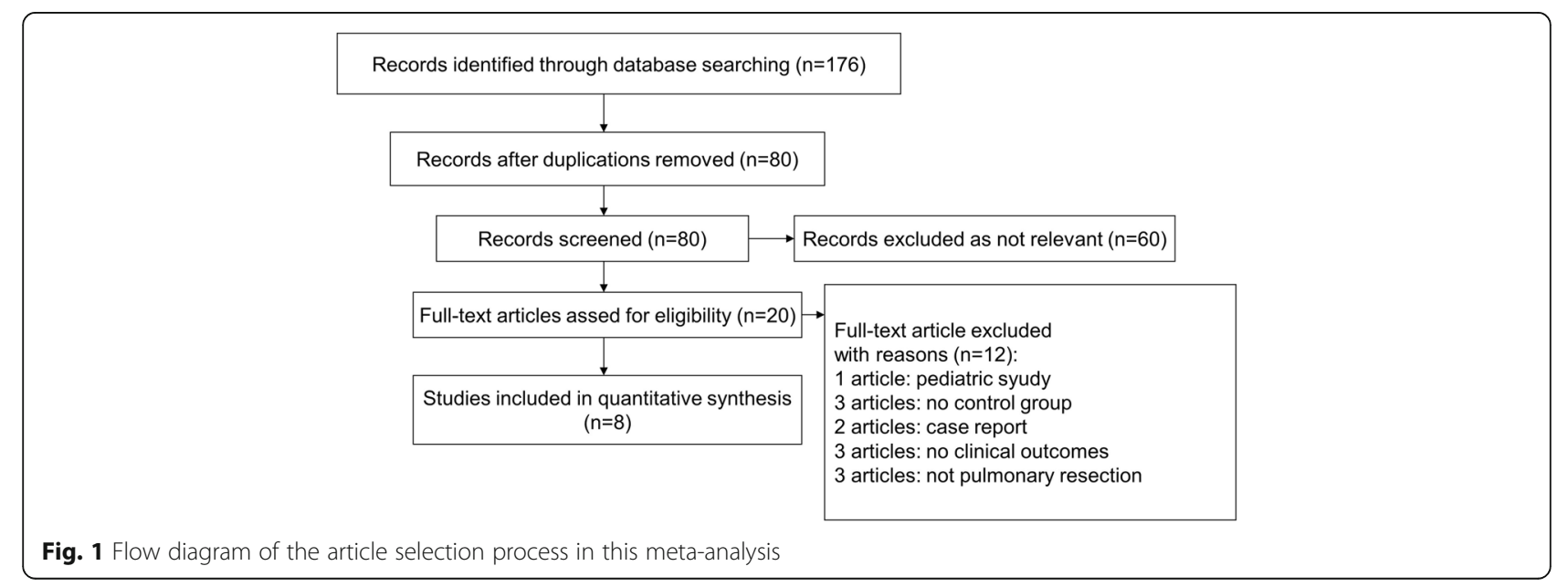


Table 1 Characteristics of Included Studies

\begin{tabular}{lllllll}
\hline Studies & Year Country & \multicolumn{2}{l}{$\begin{array}{l}\text { Number of } \\
\text { patients }\end{array}$} & $\begin{array}{l}\text { Study } \\
\text { design }\end{array}$ & $\begin{array}{l}\text { Study } \\
\text { quality }\end{array}$ \\
\cline { 3 - 5 } & & & Digital & Traditional & \\
\hline Takamochi & 2017 & Japan & 135 & 164 & RCT & High (5) \\
Waele & 2017 & Canada & 53 & 50 & RCT & High (5) \\
Miller & 2016 & USA & 20 & 40 & POS & S3; C1; O3 \\
Shoji & 2016 & Japan & 112 & 121 & ROS & S3; C1; O3 \\
Filosso & 2015 & Italy & 40 & 40 & POS & S3; C1; O3 \\
Gilbert & 2015 & Canada & 87 & 85 & RCT & High (5) \\
Pompili & 2014 & International & 191 & 190 & RCT & High (5) \\
Brunelli & 2009 & Italy & 82 & 77 & RCT & High (4)
\end{tabular}

$R C T$ randomized control trial, $R O S$ retrospective observational study, $P O S$ prospective observational study

standardized mean difference (SMD) with a 95\%CI using the Inverse Variance method. Forest graphs were applied to present the meta-analysis results. The statistical heterogeneity of included literatures was assessed by $\mathrm{I}^{2}$ statistic. $\mathrm{I}^{2}$ values $\leq 50 \%, 50-74$ and $\geq 75 \%$ indicate low, moderate and high heterogeneity [9]. A fixed-effects model was chosen to perform the meta-analysis when the $\mathrm{I}^{2}$ value was $\leq 50 \%$. A random-effects model was chosen when the $\mathrm{I}^{2}$ value was $>50 \%$. $P$-value $<0.05$ was considered as statistically significant.

\section{Results}

\section{Description of the included studies}

There were 80 articles identified through the literature search process. Among the 80 articles, 60 articles were excluded as not being relevant. The remaining 20 studies were assessed for eligibility, and 8 studies (5 randomized control trails and 3 observational studies) [10-17] comprising 1487 patients met our eligibility criteria and were included in this meta-analysis (Fig. 1). Among the 1487 patients, digital chest drainage systems were used in 720 patients, and traditional chest drainage systems were used in 767 patients. The characteristics of the studies included are shown in Table 1. The baseline characteristics of the patients are shown in Table 2.

\section{Prolonged air leak}

Five studies evaluated the incidence of prolonged air leak $[11,12,14,16,17]$. Digital chest drainage system significantly reduced the risk of prolonged air leak compared with traditional chest drainage system $(\mathrm{RR}=0.54,95 \% \mathrm{CI} 0.40-0.73, p<0.0001$; Fig. 2). No significant heterogeneity was observed in the pooled group of studies $\left(\mathrm{I}^{2}=48 \%, \mathrm{Chi}^{2}=7.66, p=0.10\right.$; Fig. 2$)$. Among the five studies, four studies were randomized control trials [11, 12, 16, 17], in this subgroup, the risk of prolonged air leak was still lower in digital group than in traditional group $(\mathrm{RR}=0.59,95 \% \mathrm{CI}$ $0.43-0.82, p=0.002)$. One study was observational study [14], which the risk of prolonged air leak was also lower in digital group than in traditional group $(\mathrm{RR}=0.33,95 \% \mathrm{CI} 0.15-0.75, p=0.008)$.

\section{Duration of chest drainage}

Eight studies reported the duration of chest drainage [10-17]. Among the 8 studies, two studies presented the data in a mean \pm standard deviation form [11, 14], and meta-analysis of these two studies suggested that digital chest drainage system significantly reduced the duration of chest drainage compared with traditional chest drainage system $(\mathrm{SMD}=-0.35,95 \% \mathrm{CI}-0.60--0.09$, $p=0.008$; Fig. 3). The mean or median duration of chest drainage in the 8 studies were summarized in Table 3.

\section{Length of hospital stay}

Seven studies reported the length of hospital stay [11-17]. Among the 7 studies, two studies presented the data in a mean \pm standard deviation form [11, 14], and meta-analysis of these two studies suggested that

Table 2 The baseline characteristics of the patients

\begin{tabular}{|c|c|c|c|c|c|c|c|c|}
\hline \multirow[t]{2}{*}{ Studies } & \multicolumn{2}{|c|}{ Male (\%) } & \multicolumn{2}{|l|}{ Age (years) } & \multicolumn{2}{|c|}{ VATS (\%) } & \multicolumn{2}{|c|}{ Lobectomy (\%) } \\
\hline & Digital & Traditional & Digital & Traditional & Digital & Traditional & Digital & Traditional \\
\hline Takamochi 2017 & 51.8 & 48.7 & $66.6 \pm 12.6$ & $67.9 \pm 10.9$ & NA & NA & 77 & 81.1 \\
\hline Waele 2017 & 48.1 & 51.9 & $68.5 \pm 10.3$ & $64.8 \pm 10.6$ & 56.2 & 43.8 & 50.8 & 49.2 \\
\hline Miller 2016 & 55 & 60 & $63(48-77)$ & $63(52-79)$ & 100 & 100 & 85 & 85 \\
\hline Shoji 2016 & 69 & 86 & $67(20-88)$ & 65 (19-87) & NA & NA & 66 & 62 \\
\hline Filosso 2015 & 60 & 60 & $69 \pm 7.9$ & $67 \pm 8.3$ & NA & NA & 80 & 78 \\
\hline Gilbert 2015 & 36.5 & 36.8 & $68(60-72)$ & $68(60-75)$ & 73.6 & 70.6 & 70.1 & 83.5 \\
\hline Pompili 2014 & 49 & 55 & $66.5 \pm 12.1$ & $65.9 \pm 10.2$ & 82 & 80 & 83 & 88 \\
\hline Brunelli 2009 & 70 & 77 & $66.1 \pm 12.8$ & $67.3 \pm 8.4$ & NA & NA & NA & NA \\
\hline
\end{tabular}




\begin{tabular}{|c|c|c|c|c|c|c|c|c|}
\hline Study or Subgroup & $\begin{array}{l}\text { Digital } \\
\text { Events }\end{array}$ & Total & $\begin{array}{l}\text { Traditio } \\
\text { Events }\end{array}$ & Total & Weight & $\begin{array}{l}\text { Risk Ratio } \\
\mathrm{M}-\mathrm{H} \text {, Fixed, } 95 \% \mathrm{Cl}\end{array}$ & $\begin{array}{r}\text { Risk F } \\
\text { M-H, Fixe }\end{array}$ & $\begin{array}{l}\text { Ratio } \\
\text { ed, } 95 \% \mathrm{Cl}\end{array}$ \\
\hline Brunelli 2009 & 22 & 82 & 29 & 77 & $30.5 \%$ & $0.71[0.45,1.13]$ & $\rightarrow$ & \\
\hline Filosso 2015 & 6 & 40 & 18 & 40 & $18.4 \%$ & $0.33[0.15,0.75]$ & & \\
\hline Pompili 2014 & 12 & 191 & 29 & 190 & $29.7 \%$ & $0.41[0.22,0.78]$ & & \\
\hline Takamochi 2017 & 11 & 135 & 13 & 164 & $12.0 \%$ & $1.03[0.48,2.22]$ & & \\
\hline Waele 2017 & 2 & 53 & 9 & 50 & $9.5 \%$ & $0.21[0.05,0.92]$ & & \\
\hline Total (95\% Cl) & & 501 & & 521 & $100.0 \%$ & $0.54[0.40,0.73]$ & & \\
\hline Total events & 53 & & 98 & & & & & \\
\hline \multicolumn{7}{|c|}{$\begin{array}{l}\text { Heterogeneity: } \text { Chi }^{2}=7.66, d f=4(P=0.10) ; I^{2}=48 \% \\
\text { Test for overall effect: } Z=3.97(P<0.0001)\end{array}$} & $\begin{array}{ll}0.01 & 0.1 \\
\text { Favours [Digital] }\end{array}$ & $\begin{array}{ccc}1 & 10 & 100 \\
\text { Favours } & \text { [Traditional] }\end{array}$ \\
\hline
\end{tabular}

digital chest drainage system significantly reduced the length of hospital stay compared with traditional chest drainage system $(\mathrm{SMD}=-0.35,95 \% \mathrm{CI}-0.61-0.09$, $p=0.007$; Fig. 4). The mean or median length of hospital stay in the 7 studies were summarized in Table 3.

\section{Discussion}

In the present meta-analysis and systematic review, we found that compared to traditional chest drainage system, digital chest drainage system reduced the risk of incidence of prolonged air leak, and shortened the duration of chest drainage and length of hospital stay in patients after pulmonary resection.

PAL remains a common complication after pulmonary resection. Several studies had shown that PAL was associated with longer hospital stay and more hospital costs $[18,19]$. It was also suggested that PAL was associated with an increased rate of postoperative morbidity, such as empyema, fever and pneumonia [20]. The risk of PAL can be predicted by several preoperative and intraoperative factors such as a low predicted postoperative forced expiratory volume in $1 \mathrm{~s}$ (ppoFEV1), pleural adhesions and upper lobectomy [20]. Besides, improvement in postoperative chest drainage system is an important approach to reduce PAL rate and accelerate the recovery.

There are several advantages of digital chest drainage system in management of patients after pulmonary resection. First of all, the digital system can regulate its suction pressure according to the condition in the pleural cavity, and the pleural pressure can be maintained at a preset level within $0.1 \mathrm{cmH}_{2} \mathrm{O}$. It had been shown that wide oscillation in early postoperative pleural pressure was associated with a higher incidence of PAL [21]. Thus, the digital chest drainage system may promote the sealing of air leaks by stabilizing the pleural pressure with minimal oscillation. Second, the digital system measures the extent of air leak objectively, and the historical data can be exported and reviewed. Thus, the digital chest drainage system reduces the interobserver variability, and helps medical personnel decide when to remove the chest tube more accurately. It had been proved by several clinical trials that digital chest drainage system not only reduced interobserver variability between different groups of medical staffs (surgeons, residents and nurses) [22], but also between surgeons with comparable experience [23]. The reduced interobserver variability leads to shorter duration of chest drainage and length of hospital stay. Furthermore, the digital system facilitates an early patient mobilization and improves postoperative physiotherapy, which can reduce the risk of secretion and pneumonia, and facilitates pulmonary re-expansion [14]. Finally, the digital device such as the Thopaz chest drain system (Medela Switzerland) can serve as a portable suction unit, and

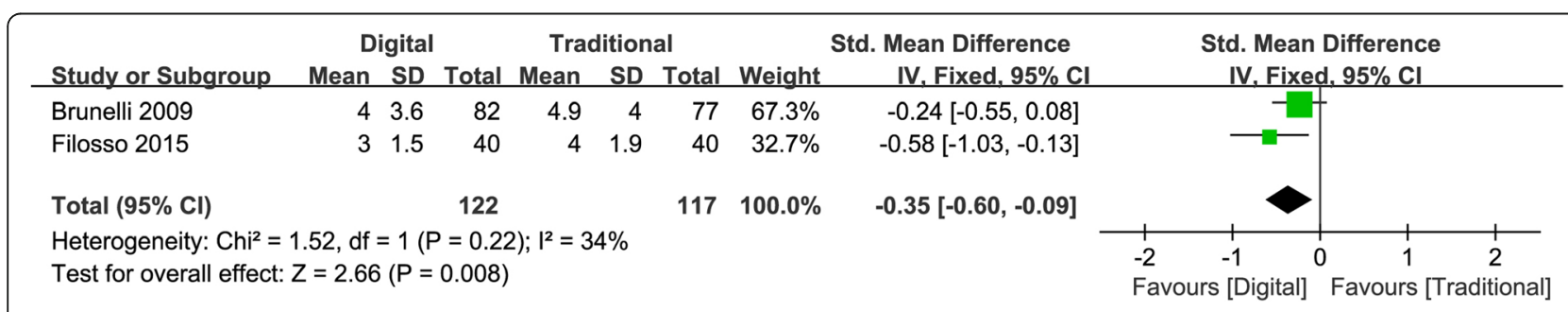

Fig. 3 Forest graph presenting duration of chest drainage. 95\%Cl: 95\% confidence interval 
Table 3 Duration of chest drainage and hospital stay

\begin{tabular}{|c|c|c|}
\hline Studies & Duration of chest drainage (days), digital vs traditional & $\begin{array}{l}\text { Length of hospital stay } \\
\text { (days), digital vs traditional }\end{array}$ \\
\hline Takamochi $2017^{\text {b }}$ & 2.0 vs $3.0, p=0.149$ & 6.0 vs $7.0, p=0.548$ \\
\hline Waele $2017^{\mathrm{a}}$ & 2.3 vs $2.5, p=0.055$ & 4.8 vs $4.9, p=0.403$ \\
\hline Miller $2016^{b}$ & 3.7 vs $5.3, p=0.01$ & 4.1 vs $5.6, p=0.05$ \\
\hline Shoji $2016^{a}$ & 2.7 vs $3.7, p=0.004$ & NA \\
\hline Filosso $2015^{a}$ & 3 vs $4, p=0.0009$ & 7 vs $8, p=0.0385$ \\
\hline Gilbert $2015^{\text {b }}$ & 4.9 vs $5.6, p=0.11$ & 6.0 vs $6.0, p=0.36$ \\
\hline Pompili $2014^{a}$ & 3.7 vs $4.7, p=0.001$ & 4.6 vs $5.6, p<0.0001$ \\
\hline Brunelli $2009^{a}$ & 4.0 vs $4.9, p=0.0007$ & 5.4 vs $6.3, p=0.007$ \\
\hline
\end{tabular}

NA not available

amean

${ }^{\mathrm{b}}$ median

patients can be discharged earlier with this system [24].

Since the traditional chest drainage system is subjective and inaccurate in judging air leak, there is risk of removing the chest tube prematurely. In that situation, chest tube reinsertion is needed. A clamping test had traditionally been taken to prevent this error. It had been suggested by Takamochi et al. that over $50 \%$ patients underwent clamping test before removing the chest tube in the traditional group, while none clamping test was taken in the digital group [17]. It had also been shown by Gilbert et al. that chest tube reinsertions for worsening pneumothorax or subcutaneous emphysema after chest tube removal occurred only in the traditional group, none chest tube reinsertion happened in the digital group [13].

Some clinicians hypothesized that the intermittent suction pressure provided by the digital system may reduce the pressure gradient for fluid filtration across the pleural membrane and lighten the inflammatory response. However, the study conducted by Waele et al. did not find such effect [16].

Apart from objective outcomes, subjective outcome (such as patient satisfaction) is also important in evaluating chest drainage system. The multicenter study conducted by Pompili et al. evaluated the patient satisfaction with digital chest drainage system, and the result suggested that patients in the digital group had a more positive perception of the chest drainage, which was associated the comfort, portability and convenience of the digital system [12].

Recently, a meta-analysis of randomized controlled trials conducted by Zhou et al. suggested that digital chest drainage following pulmonary surgery reduced the duration of chest tube placement, length of hospital stay, air leak duration and postoperative cost [25]. Compared to their study, the present systematic review focused on patients after pulmonary resection, and obtained similar results. Another recent study discussed the postoperative air leak pattern in lung cancer patients after pulmonary resection with the help of digital chest drainage system, which suggested that the detailed air leak pattern can be used to predict the duration of air leakage and chest tube drainage [26].

\section{Conclusion}

The present systematic review shows that digital chest drainage system is expected to benefit patients to attain faster recovery and higher life quality as well as to reduce the risk of postoperative complications. Further RCTs with larger sample size are still needed to more clearly elucidate the advantages of digital chest drainage system.

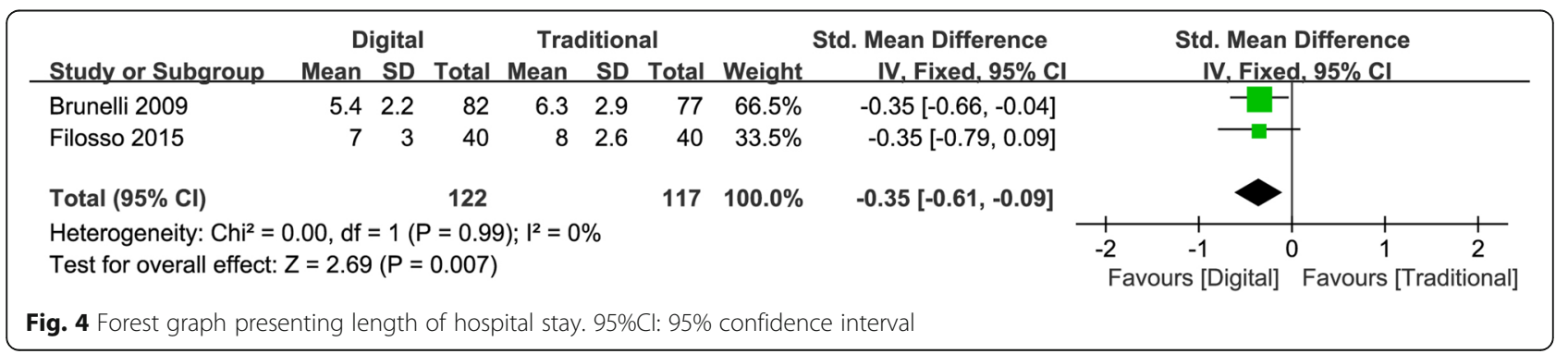




\section{Abbreviations}

Cl: Confidence interval; PAL: Prolonged air leak; ppoFEV1: Predicted postoperative forced expiratory volume; RCT: Randomized controlled trial; RR: Risk ratio; SMD: Standardized mean difference

\section{Acknowledgements}

Not applicable.

\section{Funding}

This work was supported by the National Natural Science Foundation of China (Grant No. 81670350)

\section{Availability of data and materials}

Please contact author for data requests.

\section{Authors' contributions}

(I) Conception and design: YZ; (II) Administrative support: LM, YZ; (III) Provision of study materials or patients: HW, WH; (IV) Collection and assembly of data: HW, WH; (V) Data analysis and interpretation: All authors; (VI) Manuscript writing: All authors; (VII) Final approval of manuscript: All authors.

\section{Ethics approval and consent to participate}

Not applicable.

\section{Consent for publication}

Not applicable.

\section{Competing interests}

The authors declare that they have no competing interests.

\section{Publisher's Note}

Springer Nature remains neutral with regard to jurisdictional claims in published maps and institutional affiliations.

\section{Author details}

${ }^{1}$ Department of Surgery, Zhejiang University Hospital, Zhejiang University, Hangzhou, China. 'Department of Cardiothoracic Surgery, First Affiliated Hospital, Zhejiang University School of Medicine, Hangzhou 310003, China.

Received: 19 July 2018 Accepted: 14 January 2019

Published online: 18 January 2019

\section{References}

1. Mueller MR, Marzluf BA. The anticipation and management of air leaks and residual spaces post lung resection. J Thorac Dis. 2014;6(3):271-84.

2. Brunelli A, Cassivi SD, Halgren L. Risk factors for prolonged air leak after pulmonary resection. Thorac Surg Clin. 2010;20(3):359-64.

3. Varela G, Jiménez MF, Novoa N, Aranda JL. Estimating hospital costs attributable to prolonged air leak in pulmonary lobectomy. Eur J Cardiothorac Surg. 2005;27(2):329-33.

4. Brunelli A, Xiume F, Al Refai M. Air leaks after lobectomy increase the risk of empyema but not of cardiopulmonary complications: a case-matched analysis. Chest. 2006;130(4):1150-6.

5. George RS, Papagiannopoulos K. Advances in chest drain management in thoracic disease. J Thorac Dis. 2016;8(Suppl 1):S55-64.

6. Zhang $Y, M a$ L. Effect of preoperative angiotensin-converting enzyme inhibitor on the outcome of coronary artery bypass graft surgery. Eur J Cardiothorac Surg. 2015;47(5):788-95.

7. Jadad AR, Moore RA, Carroll D, Jenkinson C, Reynolds DJ, Gavaghan DJ, et al. Assessing the quality of reports of randomized clinical trials: is blinding necessary? Control Clin Trials. 1996;17(1):1-12.

8. Moher D, Liberati A, Tetzlaff J, Altman DG, PRISMA Group. Preferred reporting items for systematic reviews and meta-analyses: The PRISMA statement. PLoS Med. 2009;6(7):e1000097.

9. Higgins JPT, Green S. Cochrane Handbook for Systematic Reviews of Interventions Version 5.1.0 [updated March 2011]. Cochrane Collab:2011.

10. Shoji F, Takamori S, Akamine T, Toyokawa G, Morodomi Y, Okamoto T, et al. Clinical evaluation and outcomes of digital chest drainage after lung resection. Ann Thorac Cardiovasc Surg. 2016;22(6):354-8.
11. Brunelli A, Salati M, Refai M, Di Nunzio L, Xiumé F, Sabbatini A. Evaluation of a new chest tube removal protocol using digital air leak monitoring after lobectomy: a prospective randomised trial. Eur J Cardiothorac Surg. 2010; 37(1):56-60.

12. Pompili C, Detterbeck F, Papagiannopoulos K, Sihoe A, Vachlas K, Maxfield MW, et al. Multicenter international randomized comparison of objective and subjective outcomes between electronic and traditional chest drainage systems. Ann Thorac Surg. 2014;98(2):490-6 discussion 496-7.

13. Gilbert S, McGuire AL, Maghera S, Sundaresan SR, Seely AJ, Maziak DE, et al. Randomized trial of digital versus analog pleural drainage in patients with or without a pulmonary air leak after lung resection. J Thorac Cardiovasc Surg. 2015;150(5):1243-9.

14. Filosso PL, Nigra VA, Lanza G, Costardi L, Bora G, Solidoro P, et al. Digital versus traditional air leak evaluation after elective pulmonary resection: a prospective and comparative mono-institutional study. J Thorac Dis. 2015; 7(10):1719-24.

15. Miller DL, Helms GA, Mayfield WR. Digital drainage system reduces hospitalization after video-assisted thoracoscopic surgery lung resection. Ann Thorac Surg. 2016;102(3):955-61.

16. De Waele M, Agzarian J, Hanna WC, Schieman C, Finley CJ, Macri J, et al. Does the usage of digital chest drainage systems reduce pleural inflammation and volume of pleural effusion following oncologic pulmonary resection?-a prospective randomized trial. J Thorac Dis. 2017;9(6): 1598-606.

17. Takamochi K, Nojiri S, Oh S, Matsunaga T, Imashimizu K, Fukui M, et al. Comparison of digital and traditional thoracic drainage systems for postoperative chest tube management after pulmonary resection: A prospective randomized trial. J Thorac Cardiovasc Surg. 2017.

18. Abolhoda A, Liu D, Brooks A, Burt M. Prolonged air leak following radical upper lobectomy: an analysis of incidence and possible risk factors. Chest. 1998;113(6):1507-10.

19. Melendez JA, Barrera R. Predictive respiratory complication quotient predicts pulmonary complications in thoracic surgical patients. Ann Thorac Surg. 1998;66(1):220-4.

20. Brunelli A, Monteverde M, Borri A, Salati M, Marasco RD, Fianchini A. Predictors of prolonged air leak after pulmonary lobectomy. Ann Thorac Surg. 2004:77(4):1205-10 discussion 1210.

21. Brunelli A, Cassivi SD, Salati M, Fibla J, Pompili C, Halgren LA, et al. Digital measurements of air leak flow and intrapleural pressures in the immediate postoperative period predict risk of prolonged air leak after pulmonary lobectomy. Eur J Cardiothorac Surg. 2011;39(4):584-8.

22. McGuire AL, Petrcich W, Maziak DE, Shamji FM, Sundaresan SR, Seely AJ, et al. Digital versus analogue pleural drainage phase 1: prospective evaluation of interobserver reliability in the assessment of pulmonary air leaks. Interact Cardiovasc Thorac Surg. 2015;21(4):403-7.

23. Varela G, Jiménez MF, Novoa NM, Aranda JL. Postoperative chest tube management: measuring air leak using an electronic device decreases variability in the clinical practice. Eur J Cardiothorac Surg. 2009;35(1):28-31.

24. Rathinam S, Bradley A, Cantlin T, Rajesh PB. Thopaz portable suction Systems in Thoracic Surgery: an end user assessment and feedback in a tertiary unit. J Cardiothorac Surg. 2011;6:59.

25. Zhou J, Lyu M, Chen N, Wang Z, Hai Y, Hao J, et al. Digital chest drainage is better than traditional chest drainage following pulmonary surgery: a metaanalysis. Eur J Cardiothorac Surg. 2018. https://doi.org/10.1093/ejcts/ezy141 [Epub ahead of print].

26. Shintani Y, Funaki S, Ose N, Kawamura T, Kanzaki R, Minami M, et al. Air leak pattern shown by digital chest drainage system predict prolonged air leakage after pulmonary resection for patients with lung cancer. J Thorac Dis. 2018;10(6):3714-21. 